\title{
Functional and radiological outcome in surgically managed posterior wall and column fractures of acetabulum
}

\author{
K. Nageswara Rao, Ronak Dinesh Soni*, C. Nagesh, P. A. Shravan Kumar, B. Arvind Kumar
}

Department of Orthopedics, Nizams Institute of Medical Sciences, Hyderabad, Telangana, India

Received: 27 July 2021

Accepted: 02 September 2021

\section{*Correspondence:}

Dr. Ronak Dinesh Soni,

E-mail: sonishreyashh@gmail.com

Copyright: ( $)$ the author(s), publisher and licensee Medip Academy. This is an open-access article distributed under the terms of the Creative Commons Attribution Non-Commercial License, which permits unrestricted non-commercial use, distribution, and reproduction in any medium, provided the original work is properly cited.

\section{ABSTRACT}

Background: The incidence of acetabular fractures has increased following road traffic accidents. The aim of the study is to evaluate functional and radiological outcome in surgically managed posterior wall and column fractures of acetabulum.

Methods: This is a prospective study done at Nizam's Institute of Medical Sciences, Hyderabad between May 2018 and May 2020. The sample size is 20 patients between the age group 18-60 years who presented to the hospital with closed posterior wall and/or column fractures of acetabulum with or without posterior dislocation of hip joint. Functional outcome is assessed by using the modified Merle D' Aubigne Postel clinical grading system, radiological outcome by Matta et al and perioperative complication are assessed by retrospectively analyzing medical records and radiographics examination.

Results: Functional outcome according to Merle D' Aubigne and Postel score 16 patients (75\%) showed good, 3 patients $(20 \%)$ showed fair, 1 patient $(5 \%)$ showed poor outcome. Radiological outcome according to Matta criteria, 16 patients $(75 \%)$ showed excellent quality of joint reduction, 4 patients $(25 \%)$ showed good quality of reduction of joint. There was significant correlation between anatomic reduction of the joint surface and functional outcome of the patient in our study ( $\mathrm{p}$ value <0.05).

Conclusions: Accurate joint reduction is of utmost importance in reduction of posterior wall or column fractures of acetabulum as posterior wall is the weight bearing zone. Functional outcome depends on fracture type, associated injuries, selection of patient, time between injury and surgery and postoperative rehabilitation.

Keywords: Posterior wall of acetabulum, Matta criteria, Merle D' Aubigne score

\section{INTRODUCTION}

Acetabular fractures are among the most complex injuries treated by orthopaedic surgeons. Acetabular fractures are usually associated with injury to adjacent soft tissues and neurovascular structures. Robert Judet and Emile Letournel helped us understand surgical approaches, technique of fracture reduction, postoperative complications. ${ }^{1,2}$ Studies by Letournel and Judet and by Matta have shown that to attain the best results, hip joint congruity and stability must be accompanied by an anatomic (defined as less than $2 \mathrm{~mm}$ of residual displacement) reduction of the displaced articular surface. ${ }^{3,4}$ Therefore, accurate reduction of the intraarticular fracture fragments is critical for a successful outcome, as is maintenance of this reduction by internal fixation.

\section{Aims and objectives}

Aims and objectives were: to study the functional and radiological outcome in surgically managed displaced posterior wall and column fractures of acetabulum; to study the post-operative complications; and to achieve normal range of motion of hip joint. 


\section{METHODS}

It was a prospective study done at Nizam's Institute of Medical Sciences, Hyderabad between May 2018 and May 2020. The sample size was 20 patients between the age group 18-60 years who presented to the hospital with closed posterior wall and/or column fractures of acetabulum with or without posterior dislocation of hip joint. Patients with open fractures of acetabulum and patients with anterior wall or column or transverse type or T-shaped fractures and patients surgically unfit were excluded from the study.

\section{Method of assessment}

Patients with acetabular fractures were evaluated with radiographs (AP view, Iliac oblique and obturator oblique views), computed tomography (CT) and $3 \mathrm{D}$ reconstruction CT scans preoperatively. Anthropometric data, comorbidities, type of fracture, neuro-vascular status, associated injuries, surgical approach, fixation method used, complications, hospital stay and outcome were recorded. Modified Merle d' Aubigne scoring system was used to measure the functional outcome and Matta's criteria used for radiologically evaluating joint congruency.

\section{Surgical procedure}

We included patients admitted to our hospital with posterior wall and column fractures of acetabulum between the ages 18 to 60 years. All the patients were evaluated by advanced trauma life support (ATLS) protocols to rule out other injuries. Radiographs of the pelvis in antero-posterior view and Judet views were done. All the patients underwent 3D CT preoperatively. Hemodynamic parameters were corrected and crossconsultations obtained for patients with comorbidities. In all patients Kocher-Langenbeck approach was followed. Under regional or general anesthesia, patient in lateral position surgical site was thoroughly scrubbed, painted and drapped. Skin incision given at $5 \mathrm{~cm}$ from posterior iliac crest proximally with apex at the greater trochanter and extending the incision distally along the shaft of the femur for about $15 \mathrm{~cm}$. The gluteus maximus is incised along the muscle fibers. Sciatic nerve is identified on posterior surface of quadratus femoris and is visualized for any contusions. The obturator internus and piriformis tendon are released from greater trochanter. Gluteus minimus is elevated off from the posterior wall and any devitalized muscle is debrided. The fracture edges are debrided, reduced and fixed with recon plates. The wound is irrigated with saline and tendons of gluteus maximus, piriformis and obturator internus are repaired. Wound is closed in layers over suction drain. Aseptic dressings done. Post operatively, blood transfusion was given as necessary and antibiotic and adequate analgesic cover was placed. Low molecular weight heparin was given for 10 days postoperatively. Active toe movements and quadriceps training were initiated from day one postop. Drain removal was done on post-operative day-2 and radiograph were obtained. Partial weight bearing was started from 6 weeks post op. and complete weight bearing started 12 weeks postop. Patient was followed up monthly for first 6 months and then at 1 year.

\section{Data collection}

Age, sex, co-morbidities, mode of injury, type of fracture, whether fracture was associated with dislocation of hip, time delay in reduction of hip after dislocation, method of reduction of the joint, intra operative time, blood loss, number of blood transfusions required during preoperative period,-arm time, complications after surgery where analyzed. Modified Merle d' Aubigne score, Modified Harris hip score, Matta radiological scoring system were used to measure the outcome.

\section{Statistical analysis}

Values were calculated as mean \pm standard deviation (SD) for quantitative variables and percentages for categorical variables. Correlation between functional and radiological score is calculated using Wilcoxon rank sum test. Correlation between age and functional outcome calculated using unpaired t-test. A p value of less than 0.05 is considered statistically significance.

\section{RESULTS}

Our study analyzed functional and radiological outcome in surgically managed displaced posterior wall and column fractures of acetabulum who underwent surgery at Nizams Institute of Medical Sciences between May 2018 and May 2020 .

$95 \%$ of the study had males. Youngest patient is of 24 years and eldest patient is of 55 years Mean age is 33.8 years with SD of 10.62 years (Figure 4).

Mode of injury was road traffic accident (RTA) in 19 patients (Figure 5).

Sixteen (16) patients had no comorbidities while two (2) were hypertensive and two (2) were diabetic. Eleven (11) had sustained right sided injury, nine (9) left sided (Figure 6). Thirteen (13) patients had posterior wall fracture, six (6) posterior wall and column, one (1) with posterior column fracture (Figure 7).

Table 1: Complications.

\begin{tabular}{|ll|}
\hline Parameters & Number \\
\hline Surgical site infection & 1 \\
\hline Heterotopic ossification & 2 \\
\hline DVT & 0 \\
\hline Iatrogenic sciatic nerve injury & 0 \\
\hline AVN & 1 \\
\hline
\end{tabular}




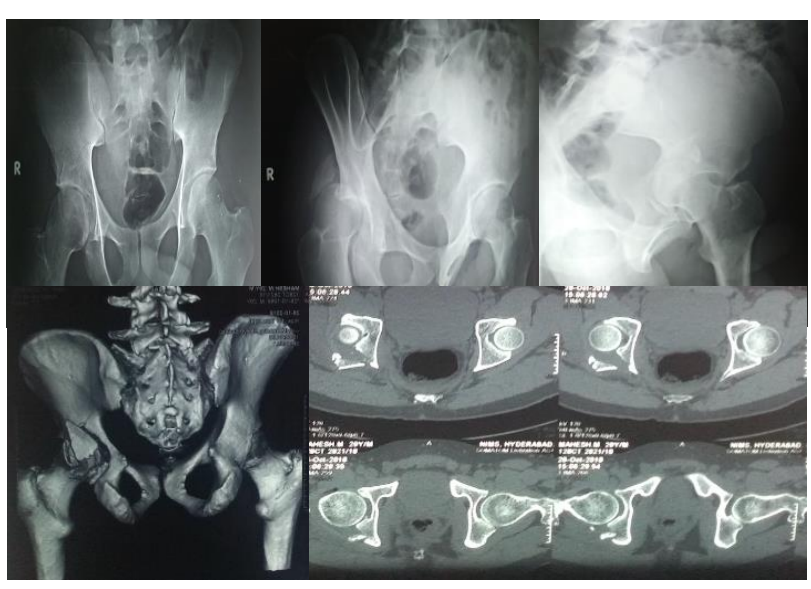

Figure 1: Anteroposterior and Judet views of posterior wall acetabulum fracture.

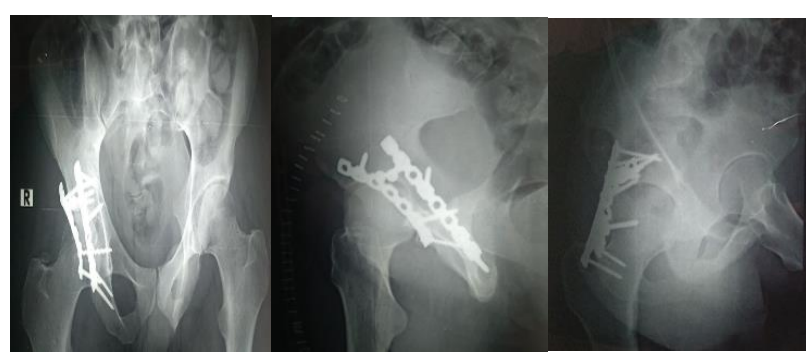

Figure 2: Postoperative radiographs.

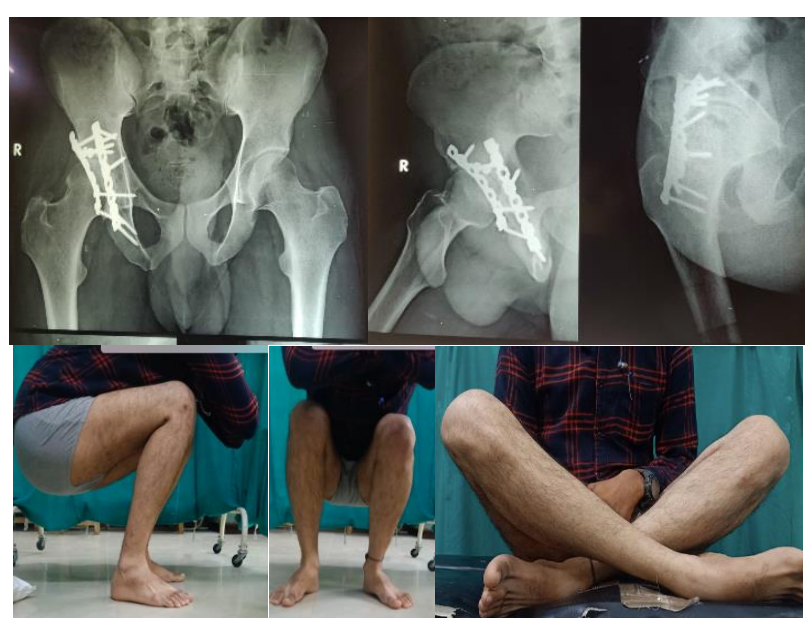

Figure 3: 1 year follow-up.

Eight (8) patients presented with posterior dislocation. Twelve (12) patients had associated injuries.

Mean time from injury to surgery was 15 days. Shortest time was 2 (two) days and longest was 60 (sixty) days.

One (1) patient had surgical site infection, two (2) had heterotopic ossification, 1 (one) patient had avascular necrosis of femoral head. 2 (two) patients had foot drop at the time of presentation. Mean operative time was 100 min. Mean blood loss was $190 \mathrm{ml}$.

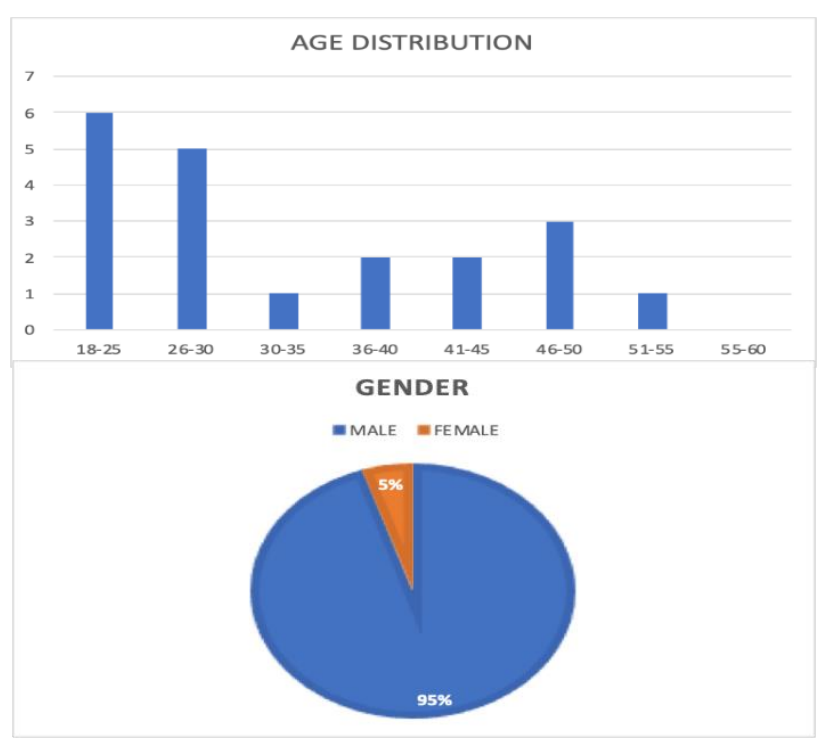

Figure 4: Age and gender distribution.

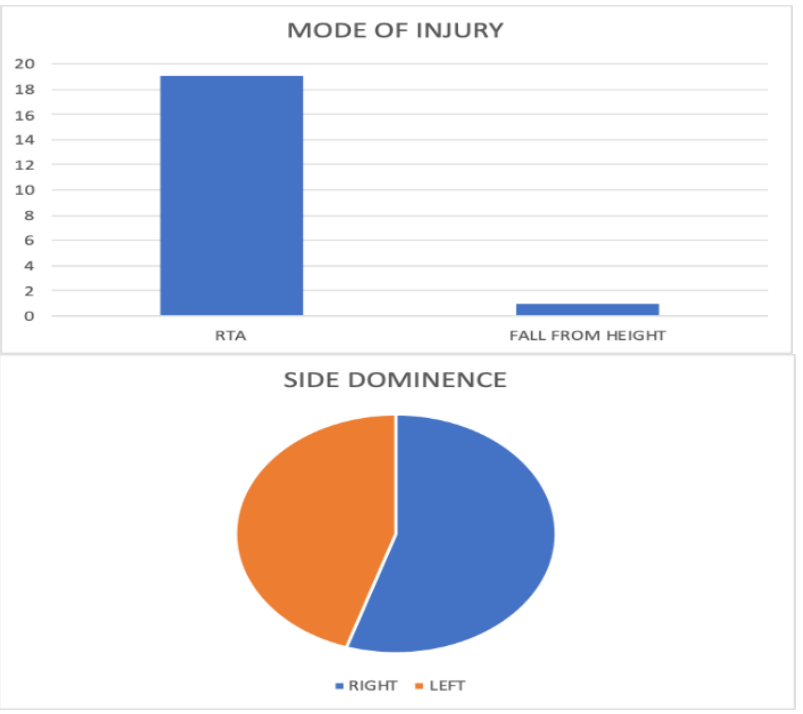

Figure 5: Mode of injury and side dominance.

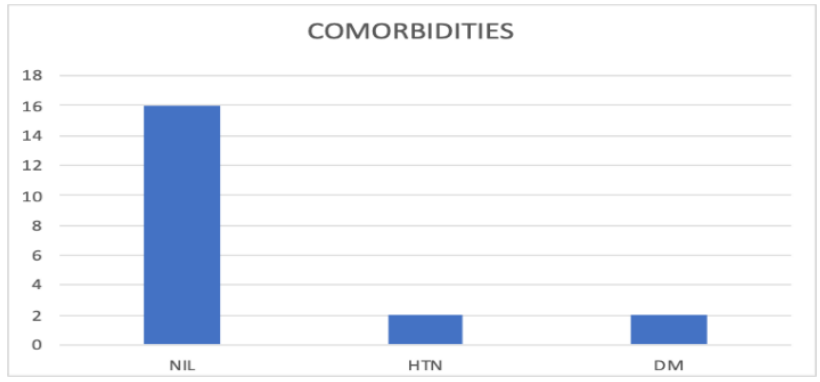

Figure 6: Comorbidities.

Sixteen (16) patients had excellent quality of reduction, 2 had good reduction and two (2) had poor reduction according to Matta scoring for quality of reduction.

According to Merle D'Aubigne functional score, one (1) excellent, sixteen (16) good, two (2) fair and two (2) had 
poor functional outcome scores (18-excellent, 15-17-good, 13-14-fair, <13-poor).

According to Modified Harris hip score, sixteen (16) had excellent, three (3) good, one (1) fair outcome scores (Figure 10).

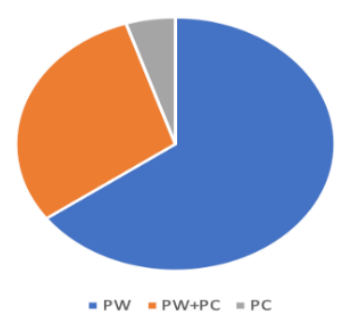

Figure 7: Distribution of type of acetabular fracture.

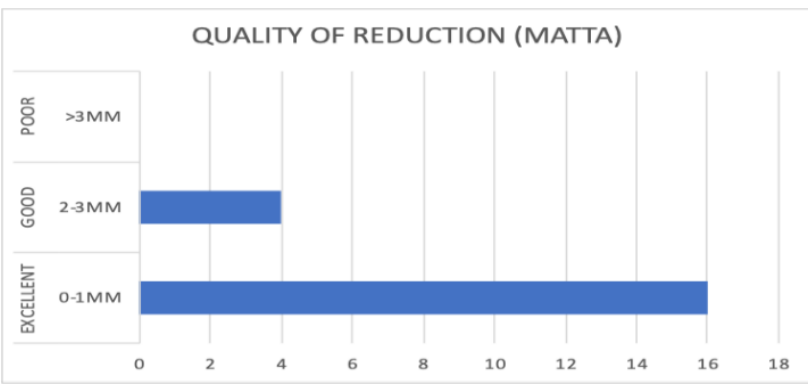

Figure 8: Quality of reduction according to matta.

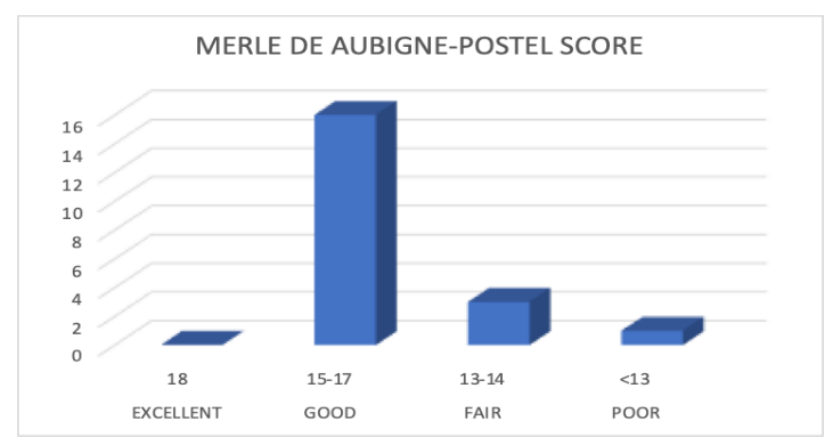

Figure 9: Functional score according to Merle De Aubinge-Postel Score.

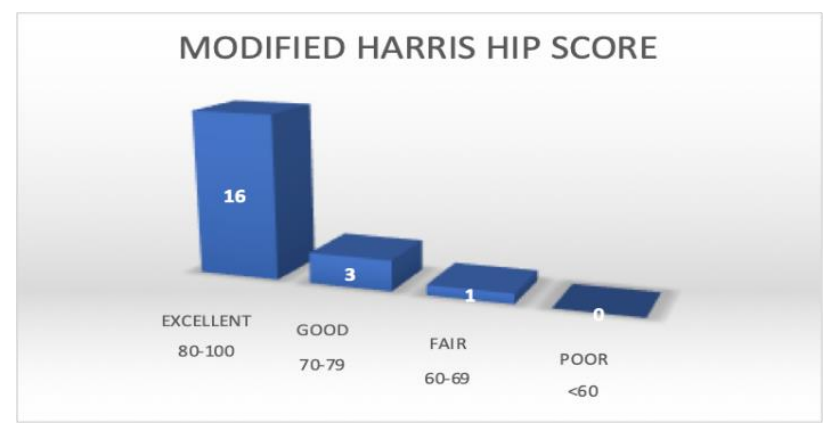

Figure 10: Functional scoring according to modified Harris Hip score.

\section{DISCUSSION}

Displaced posterior wall and column fractures of acetabulum constitute the majority of all types of acetabular fractures. As posterior wall constitutes the weight bearing part of the hip joint, any displaced fracture has tremendous effect on the outcome of hip joint stability.

Outcome depends on energy and level of injury, age of the patient, radiographic pattern of fracture and associated injuries, surgeons' awareness of acetabular anatomy, accurate reduction of fracture fragments so as to obtain pain free hip joint postoperatively.

\section{Type of fracture}

With respect to the type of fracture, posterior wall constituted $65 \%$ followed by associated posterior wall and column fractures of $30 \%$. Pure posterior column fracture constituted only $5 \%$.

Kim et al in their study of reconstruction of posterior wall acetabular fractures, 21 of $33(63.6 \%)$ patients had simple posterior wall fracture, $12(36.4 . \%)$ were complex fractures. ${ }^{5}$

\section{Lim et al described $i$}

n their study of 23 cases of acetabular fractures showed 14 cases $(60 \%)$ with posterior wall fractures. ${ }^{6}$

\section{Effect of fracture type on functional and radiological outcome}

Individuals with fractures of the acetabulum involving the posterior wall have profound functional deficits compared with the normal population. Fractures of the posterior wall with associated fractures of the posterior column appear to have a particularly poor prognosis. Anatomical reduction alone is not sufficient to restore function to normal, but residual displacement above $2 \mathrm{~mm}$ along with marginal impaction is associated with the development of early radiological arthritis.

Matta reported fractures of the posterior wall in a series of 262 acetabular fractures. ${ }^{7}$ Despite anatomical reduction as determined on plain radiographs in all 22 cases, a good or excellent clinical result was obtained in only $68 \%$.

In our study there was correlation between fracture type and functional and radiological outcome.

\section{Functional outcome measured by merle D'Aubinge score and modified Harris hip score}

Ebraheim et $\left.\mathrm{al}^{(}\right)$found that reconstruction of comminuted posterior wall fractures using the buttress technique the results for clinical outcome according to modified Merle d'Aubigne and Postel scoring system were as follows: 
excellent $11(34 \%)$, very good $9(28 \%)$, good $4(12 \%)$, fair $3(9 \%)$, and poor $5(15 \%){ }^{8}$

Kim et al discussed in their study, reconstruction of acetabular posterior wall fractures in their series. ${ }^{62}$ The Merle D'Aubigne and Postel scores at the final follow-up visit were as follows: excellent and very good in 15 patients $(45.5 \%)$, good in $5(15.2 \%)$, fair in $3(9.1 \%)$, and poor in $10(30.3 \%)$.

In our study, 16 patients $(75 \%)$ showed good, 3 patients (20\%) showed fair, 1 patient $(5 \%)$ showed poor outcome according to Merle D’Aubigne and Postel scoring system.

\section{Radiological outcome according to Matta criteria}

Quality of reduction in acetabular fracture is an independent variable in terms of final outcome. Incongruous reduction reduces contact area between femoral head and acetabulum leading to increase in force per unit area to the articular cartilage and promotes post traumatic arthritis. Matta et al states that though capability of actabulum allows limited change in distribution and perhaps reshape itself, every attempt should be made to achieve residual displacement of no more than $1 \mathrm{~mm} .{ }^{11}$

Kim et al in their series, according to the radiologic criteria of Matta, 10 patients $(30.3 \%)$ had excellent results, 14 $(42.4 \%)$ had good results, $4(12.1 \%)$ had fair results and 5 $(15.2 \%)$ were poor. ${ }^{9}$

Moed et al informed open reduction and internal fixation of posterior wall fractures of the acetabulum, in this series. ${ }^{10}$ Radiographic results were excellent in 79 hips $(84 \%)$, good in four $(4 \%)$, fair in two $(2 \%)$, and poor in nine $(10 \%)$.

In our study, 16 patients (75\%) showed excellent quality of joint reduction, 4 patients $(25 \%)$ showed good quality of reduction of joint.

Correlation between Matta radiological score and functional outcome measured with merle D'Aubinge score and modified Harris hip score

There was significant correlation between anatomic reduction of the joint surface and functional outcome of the patient in our study ( $\mathrm{p}$ value $<0.05$ ).

Patients with 0-1 mm of displacement (according to Mattas's criteria for quality of reduction) had excellent outcome when measured with modified Harris hip score and good grade when measured with Merle D'Aubinge score.

According to a study by Mesbahi et al, quality of reduction and clinical outcome strongly correlated with fracture type, post-traumatic arthritis. ${ }^{14}$
Gupta et al reported 74\%, Mayo reported 75\%, and Briffa reported $72 \%$ excellent to good clinical outcomes. ${ }^{13,15,16}$

Letournel demonstrated $80.69 \%$ good-very good-excellent results in 492 hips treated surgically within 3 weeks of injury as assessed by the method of D'Aubigne and Postel. ${ }^{13}$

\section{CONCLUSION}

Acetabular fractures have complex patho-anatomy and accurate joint reduction is of utmost importance in obtaining painless hip joint postoperatively. Overall functional outcome of the patient depends on thorough understanding of fracture configuration, proper surgical approach and expertise of the surgeon, selection of the patient, time interval between injury and surgery, and associated injuries of the patient have bearing with the overall functional outcome of the patient.

Longer follow up is needed to assess the condition of the hip for posttraumatic osteoarthritis, AVN of femoral head.

Funding: No funding sources

Conflict of interest: None declared

Ethical approval: The study was approved by the institutional ethics committee

\section{REFERENCES}

1. Judet R, Judet J, Letournel É. Fractures of the acetabulum: classification and surgical approaches for open reduction. Preliminary report. J Bone Joint Surg Am. 1964;46:1615-46.

2. Letournel É. Acetabulum fractures: classification and management. Clin Orthop Relat Res. 1980;151:81106.

3. Letournel E, Judet R. Fractures of the Acetabulum. 2nd ed. New York, NY: Springer- Verlag. 1993.

4. Matta J. Fractures of the acetabulum: accuracy of reduction and clinical results in patients managed operatively within three weeks after the injury. J Bone Joint Surg Am. 1996;78A:1632-45.

5. Kim HT, Ahn JM, Hur JO, Lee JS, Cheon SJ. Reconstruction of Acetabular Posterior Wall Fractures. Clin Orthop Surg. 2011;3(2):114-20.

6. Lim HH, Tang CL, Krishnamurty S. Operative Treatment of Acetabular Fractures. Singapore Med J. 1994;35:173-5.

7. Matta JM. Fractures of the acetabulum: accuracy of reduction and clinical results in patients managed operatively within three weeks after the injury. J Bone Joint Surg. 1996;78-A:1632-45.

8. Ebraheim NA, Patil V, Liu J, Sanford CG, Haman SP. Reconstruction of comminuted posterior wall fractures using the buttress technique: a review of 32 fractures. Int Orthop. 2007;31(5):671-5.

9. Kim HT, Ahn JM, Hur JO, Lee JS, Cheon SJ. Reconstruction of Acetabular Posterior Wall Fractures. Clin Orthop Surg. 2011;3(2):114-20. 
10. Moed BR, Willson Carr SE, Watson JT. Results of operative treatment of fractures of the posterior wall of the acetabulum. J Bone Joint Surg. 2002;84:7528.

11. Matta JM. Fractures of the acetabulum: accuracy of reduction and clinical results in patients managed operatively within three weeks after the injury. J Bone Joint Surg Am. 1996;78(11):1632-45.

12. Gupta RK, Singh H, Dev B, Kansay R, Gupta P, Garg S. Results of operative treatment of acetabular fractures from the Third World--how local factors affect the outcome. Int Orthop. 2009;33(2):347-52.

13. D'Aubigne RM, Postel M. Functinal result of hip arthroplasty with acrylic prosthesis. J Bone Joint Surg.1954;36A:451.

14. Mesbahi SAR, Ghaemmaghami A, Ghaemmaghami S, Farhadi P. Outcome after Surgical Management of Acetabular Fractures: A 7-Year Experience. Bull Emerg Trauma. 2018;6(1):37-44.

15. Mayo KA. Open reduction and internal fixation of fractures of the acetabulum. Results in 163 fractures. Clin Orthop Relat Res. 1994;305:31-7

16. Briffa N, Pearce R, Hill AM, Bircher M. Outcomes of acetabular fracture fixation with ten years' followup. J Bone Joint Surg Br. 2011;93(2):229-36.

Cite this article as: Rao KN, Soni RD, Nagesh C, Kumar PAS, Kumar BA. Functional and radiological outcome in surgically managed posterior wall and column fractures of acetabulum. Int J Res Orthop 2021;7:1139-44. 